\title{
The impact of particulate filter substrate type on the gaseous exhaust components emission
}

The article presents ceramic and metal substrate filtration efficiency in the particulate filter of a spark-ignition engine with direct fuel injection. Gaseous exhaust components were taken into account. There are many publications on the solid particles mass and number reduction, so the authors examined the effect of catalytic carriers on gaseous compounds, such as CO, NO, THC, whose content also poses a threat to human health and life, and this issue is not often described in the literature dedicated to measurements of modern internal combustion engines. During the tests, the length and carrier material effect on the emission of harmful substances in exhaust gases was determined.

Key words: filtration, emission, particulate filter, gaseous components, combustion

\section{Introduction}

Vehicle engines are constantly improved and modernized as a result of the need to meet existing exhaust emissions standards. It is not possible to meet them without the advanced exhaust gas purification systems use. From 2018, the biggest changes concerned the introduction of a particulate filter for motor vehicles with SI engines. The development of a particulate filter dedicated to gasoline engines (GPF) includes meeting certain requirements: appropriate filtration quality, structural strength, high oxygen storage capacity, small dimensions and cost.

The particulate filter combined with the three-way catalytic converter must meet the requirements for both particulate mass and number, nitrogen oxides, hydrocarbons and carbon monoxide emission limits. The performance characteristics of filters adapted for gasoline-fueled engines are different than for diesel-fueled engines. The different composition of the air-fuel mixture and the combustion temperature in both engines affect the rate of ash accumulation and the frequency of filter regeneration. The brand new filter, in which there is still no soot accumulated inside, has an efficiency of $60 \%$. To improve performance, a thicker catalytic layer is used. Increased efficiency was also noted as a result of the filtering properties of accumulated ash, as a result of which the filter efficiency increases to $80-90 \%$ [2].

Ceramic filters are the most commonly used solution in engine applications, which is associated with high temperature resistance. At the same time, the filter heating process is extended, which is also characterized by much lower resistance to mechanical damage compared to metal substrates $[1,2]$.

This does not change the number of vehicles with filters having a metal substrate, although the solution with a ceramic one is more widely described in the literature worldwide. The type of substrate, its geometrical configuration and technical parameters constitute the basic criterion for the selection of an element of the aftertreatment system for a given vehicle. Additional factors are currently being investigated, including low-ash oil and its effect on GPF [7].
The article compares the impact of the used substrate on the emission of gaseous exhaust components. Research centers around the world are focusing on mass emissions and particle numbers, although this is not the only criterion to be suggested when assessing the performance of a particle filter.

\section{Methodology}

\subsection{Research stand}

The test cycle was recorded during the drive in real traffic conditions according to RDE (Real Driving Emissions) test procedure introduced in September 2017. Real-world tests are an extension of the current WLTP (Worldwide Harmonized Light Vehicles Test Procedure) test [9]. During the actual drive, external factors such as weather conditions, congestion and the influence of the driving style are taken into account. The different colors are responsible for the type of route and the relevant speed regulations. (Fig. 1). The engine was located at the AUTOMEX engine dynamometer (Fig. 2). The engine used in laboratory test had the same technical parameters as the test vehicle (Table 1).

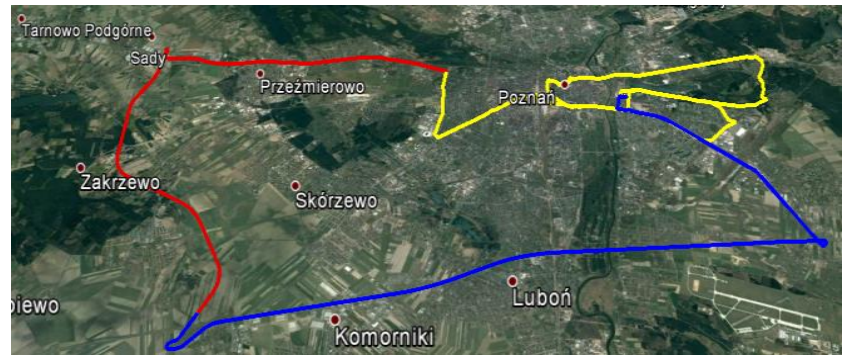

Fig. 1. Original research RDE route

The tests were carried out on a dynamic engine dynamometer equipped with an engine approved according to the Euro 5 standard with a displacement of $1197 \mathrm{~cm}^{3}$. The test route was limited to an urban and extra-urban cycle as the exhaust gas temperature for the motorway cycle was too high to be reflected on the test bench. Performing the test for the full route corresponding to the RDE cycle could 
damage the measuring equipment due to insufficient cooling of the system. Reflecting the actual operation conditions with the use of a brake stand, it is possible to test many filters with the same equipment and configuration of the test stand which reduces the cost and time associated with the need to install each filter in the exhaust system of a real vehicle.

Table 1. Tested vehicle technical data

\begin{tabular}{|l|c|}
\hline Engine type & Spark-ignition \\
\hline Displacement $\left[\mathrm{cm}^{3}\right]$ & 1197 \\
\hline Cylinders setup & inline \\
\hline Number of cylinders & 4 \\
\hline Power $[\mathrm{kW}]$ & 77 \\
\hline Maximum torque $[\mathrm{Nm}]$ & 160 \\
\hline Injection type & direct \\
\hline
\end{tabular}

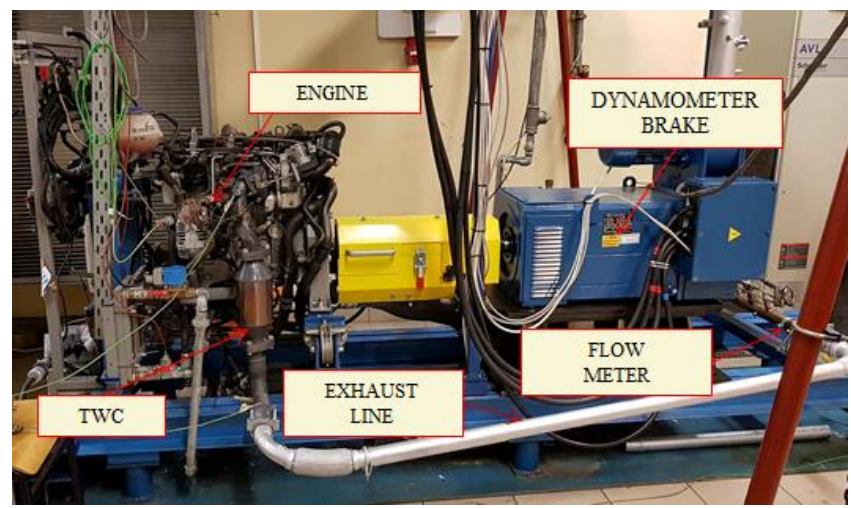

Fig. 2. View of the test stand

\subsection{Measurement equipment}

The tests were carried out using measuring equipment from the PEMS group - SEMTECH DS (Portable Emissions Measurement Systems), which is equipped with analyzers for measuring the content of harmful components in exhaust gases (Fig. 3). The exhaust mass flow probe takes a sample, which is then transported through a special tube that maintains a temperature of 191 degrees Celsius. This prevents the condensation of hydrocarbons that can cause device damage. Filtering the sample removes particulate matter. In such a sample prepared in this way, the hydrocarbon content is first determined. After the sample is cooled, it is sent to the analyzer with an ultraviolet detector, which measures the concentration of nitrogen oxide and dioxide. Carbon monoxide and carbon dioxide are tested using infrared (Non-Dispersive Infrared Detector). The last stage of the test is the measurement of the oxygen content in the exhaust gas. This is made possible by an electrochemical sensor. The SEMTECH DS analyzer has access to information contained in the vehicle's OBD system, such as rotational speed or engine load. With the help of the GPS system, it is possible to reflect the route using visualization tools. During both real and laboratory tests, the apparatus was zeroed and calibrated in accordance with the manufacturer's recommendations [4].

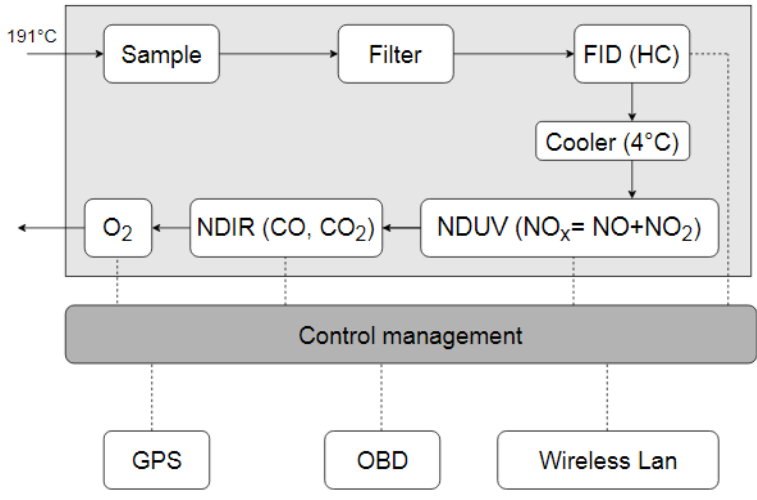

Fig. 3. SEMTECH DS - operation diagram

\subsection{Research objects}

Three configurations of the exhaust system equipped with a three-way catalyst, a particulate filter with a ceramic and a metal substrate were tested (Table 2). In addition to the material from which the interior of the filter was made, the elements differed in geometry, cell placement, length and thermal properties resulting from the material used [5]. The catalyst layer of each of the filters is the know-how of the manufacturer and has not been taken into account as a criterion for assessing filtration efficiency. The background for the research is the original three-way catalyst, which is the equipment of each approved vehicle (Fig. 5). It corresponds to exhaust emissions for a system not equipped with a particulate filter. TWC was used in each configuration of the system, initially only TWC, TWC + ceramic filter and $\mathrm{TWC}+$ metal filter.

Tab. 2. Basic characteristics of filters

\begin{tabular}{|l|c|c|}
\hline Substrate feature & \multicolumn{2}{|}{} \\
\hline Type & ceramic & metal \\
\hline Length & $120 \mathrm{~mm}$ & $160 \mathrm{~mm}$ \\
\hline Diameter & $150 \mathrm{~mm}$ & $130 \mathrm{~mm}$ \\
\hline Flow type & wall-through & flow-through \\
\hline
\end{tabular}

The ceramic substrate has an even distribution and a constant number of cells per square inch over the entire diameter of the filter (CPSI) (Fig. 6). The metal substrate was formed as a result of rolling the material with a wavy structure (Fig. 4). A filter with a ceramic substrate is characterized by the flow of exhaust gases between the walls. This improves the filtration efficiency by distributing the exhaust gas inside the filter.
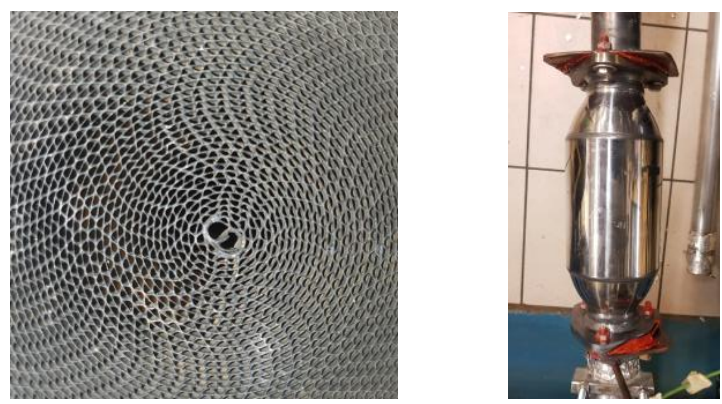

Fig. 4. View of the metal substrate inlet and particulate filter 


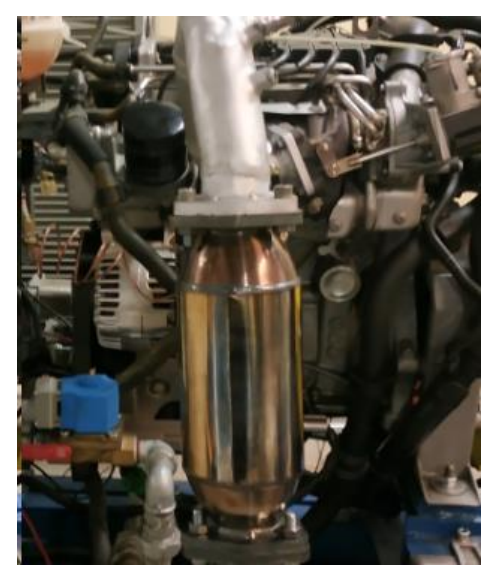

Fig. 5. View of the TWC reactor used as a background results source
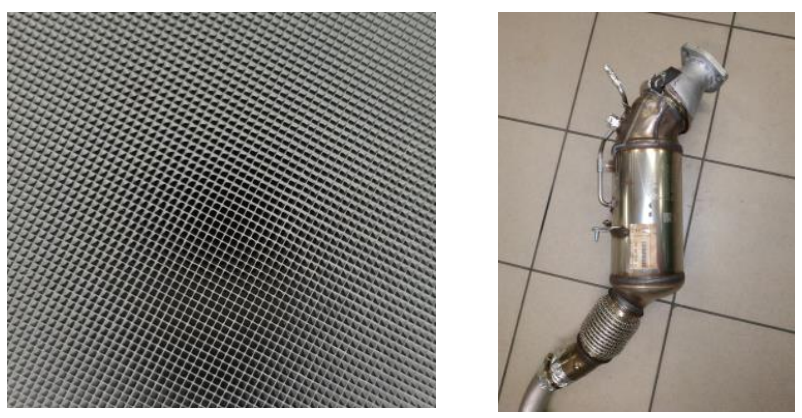

Fig. 6. View of the ceramic substrate inlet and particulate filter

\section{Research results}

The lowest $\mathrm{CO}_{2}$ emission was recorded for the metal substrate, which may be due to lower flow resistance dictated by the largest actual cell size and reduced flow resistance in the central part (Fig. 7) [6].

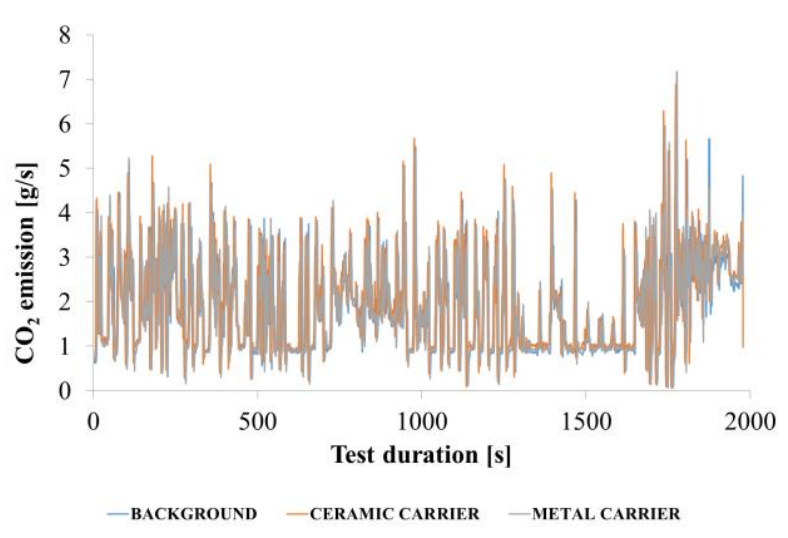

Fig. 7. Carbon dioxide emission intensity

In the case of carbon monoxide, an increased emission was recorded for a ceramic substrate, which may be caused by insufficient heating of the element and subsequent reaching the light-off temperature (Fig. 8) [10].

The phenomenon of incomplete combustion is reflected in hydrocarbon emissions (Fig. 9). The ceramic substrate has a long warm-up time, but also maintains temperature. Increased THC emission in the initial phase of the test results from the need to achieve the right temperature for more accurate combustion. The metal substrate is more susceptible to temperature fluctuations, and thus increased hydrocarbon emissions. Emission values are twice as high as for the ceramic substrate (Fig. 9).

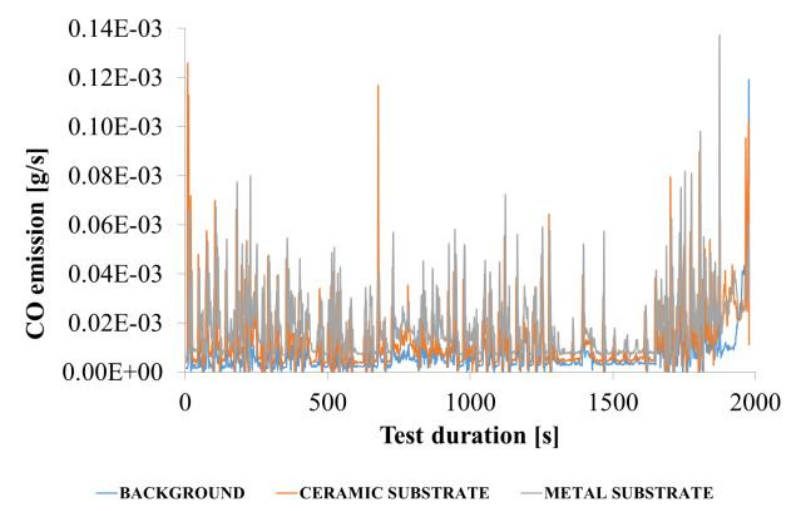

Fig. 8. Carbon dioxide emission intensity

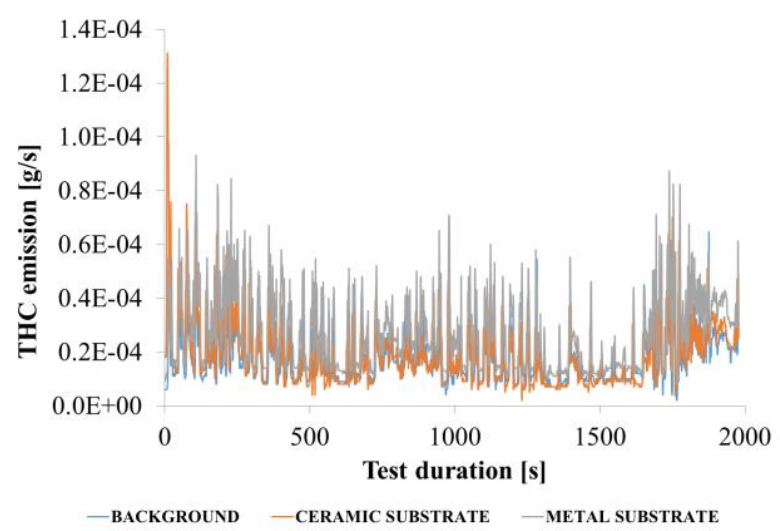

Fig. 9. Hydrocarbons emission intensity

High temperatures promote the formation of nitrogen oxides. The emission path for both substrates is similar. At the end of the test, the effectiveness of both solutions can be seen compared to a system that contains only a threeway catalytic converter (Fig. 10). Metal substrate has a greater impact on the reduction of nitrogen oxides, however, the total emission shows a greater efficiency of the ceramic substrate, which is not so susceptible to changes in thermal conditions.

The exhaust gas temperature was measured at the sampling point, i.e. at the end of the exhaust system. The first phase of the test corresponds to moving in urban conditions. Initially, the elements of the aftertreatment system absorbed the exhaust gas temperature, therefore the highest values were recorded for the system without particulate filters (Fig. 11).

In the extra-urban cycle, the temperature of all the systems was equalized, so that in the last part of the cycle, which reflects the conditions of traveling on the extra-urban route (vehicle speed between $60 \mathrm{~km} / \mathrm{h}$ and $90 \mathrm{~km} / \mathrm{h}$ ), the highest values were achieved for the ceramic substrate and the system without filter. The metal substrate, due to its physicochemical properties, cools faster, so in the final phase of the test the temperature did not equalize with the ceramic substrate. 


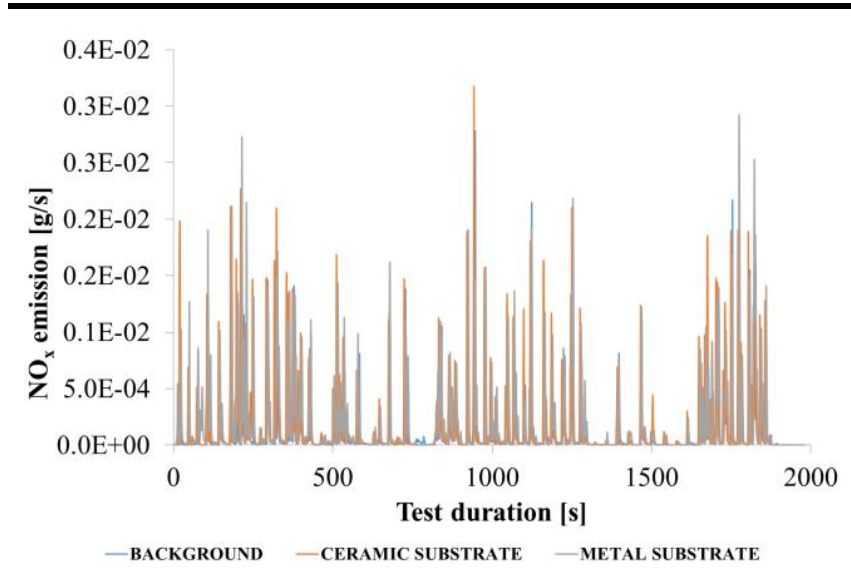

Fig. 10. Nitrogen oxides emission intensity

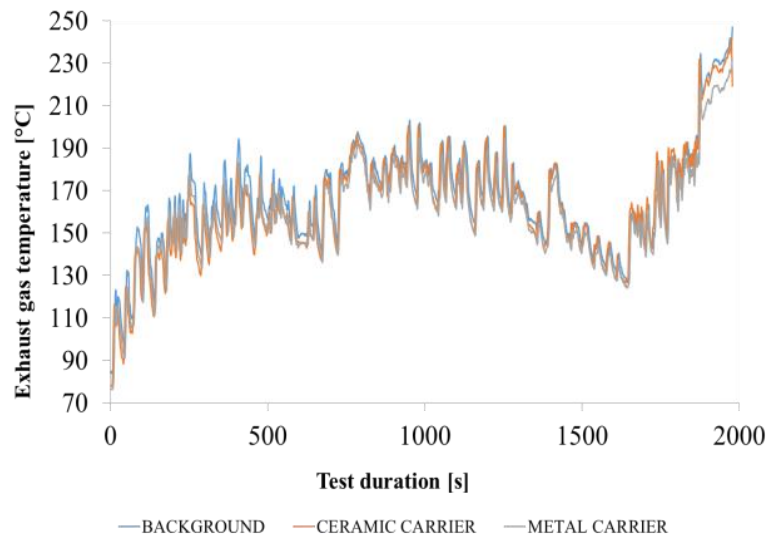

Fig. 11. Exhaust gas temperature during the test

\section{Summary}

The applicable regulations on pollutant emissions force vehicle manufacturers to use exhaust gas purification components. To achieve maximum efficiency, the solution has to be adapted to the specifics and operating conditions of the vehicle. The exhaust gas temperature of spark ignition engines is higher than for diesel fueled engines. This enables continuous filter regeneration, which ensures the removal of excess soot from the substrate during ongoing operation $[3,8]$.

The main purpose of gasoline particulate filters is their effect on reducing the content of solid particles in the exhaust gas, but it should be remembered that its operation does not remain indifferent to other exhaust gas components. Due to the small number of publications on this subject, the authors decided to conduct research in this area.

The research shows that, compared to the operation of the three-way catalyst, a filter with a ceramic substrate showed greater efficiency (Fig. 12). The exception was $\mathrm{CO}_{2}$ emissions, which could have resulted from increased flow resistance. The time for the carrier to reach the light-off temperature (the appropriate operating temperature) is longer for the ceramic carrier, therefore its effectiveness at shorter distances is lower. Incomplete combustion of the mixture was more important in the case of a metal substrate filter. High susceptibility to temperature changes occurring in the system caused an increase in THC and CO emissions. The formation of $\mathrm{NO}_{\mathrm{x}}$ is favored by the high combustion temperature of the mixture. The metal substrate undergoes temperature changes, caused for example by a sharp increase in vehicle speed.

The tests are also subjected to a combination of the ceramic filter substrate with a metal foam [6]. This is to combine the advantages of each solution, but so far no satisfactory results have been achieved due to pressure loss due to particle accumulation, therefore it is necessary to choose filters available on the market. Lack of guidelines and regulations determining the shape and other parameters of the carrier for individual treatment systems, manufacturers of particulate filters and catalytic reactors develop original technologies and designs. The freedom in choosing the shape, dimensions and density of the target results in the formation of carriers of different geometry and operational efficiency. The limitation of the test results is the difference between the performance of filters made of different materials, e.g. the type of catalytic layer. As part of further research, the authors will focus on comparing the filtration efficiency of elements made of the same materials in order to select the most effective configuration for a given type of engine.

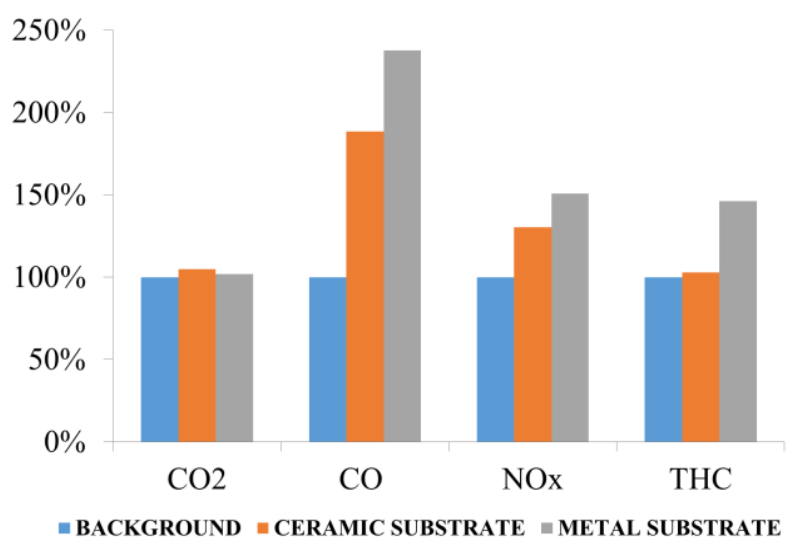

Fig. 12. Comparison of individual exhaust gas components emission related to TWC as a background values

\section{Bibliography}

[1] CUTTLER, W. Overview of ceramic materials for diesel particulate filter. Ceramic Engineering and Science Proceedings Paper 2008. https://doi.org/10.1002/9780470291184.ch61

[2] LAMBERT, C., CHANKO, T., DOBSON, D. et al. Gasoline Particle Filter Development. Emission Control Science and. Engineering. 2017, 3, 105-111.

https://doi.org/10.1007/s40825-016-0055-X

[3] LEAHU, C., TARULESCU, R., TARULESCU, R. The exhaust gas temperature control through an adequate thermalmanagement of the engine. IOP Conference Series Materials Science and Engineering. 2018. https://doi.org/10.1088/1757899X/444/7/072016 
[4] MERKISZ, J., LIJEWSKI, P., FUĆ, P. et al. Measurement of exhaust emissions under actual operating conditions with the use of PEMS: Review of selected vehicles. Improvement Trends for Internal Combustion Engines. 2018. https://doi.org/10.5772/intechopen.70442

[5] PAVLOVIC, J., CIUFFO, B., FONTARAS, G. et al. How much difference in type-approval $\mathrm{CO}_{2}$ emissions from passenger cars in Europe can be expected from changing to the new test procedure (NEDC vs. WLTP)? Transportation Research Part A: Policy and Practice 2018. https://doi.org/10.1016/j.tra.2018.02.002

[6] SARASAVADIYA, H., SHAH, M., SARKAR, I. et al. Performance of diesel particulate filter using metal foam combined with ceramic honeycomb substrate. Springer. 2018. https://doi.org/10.1007/978-981-13-2718-6

[7] SHAO, H., LAM, W., REMIAS, J. et al. Effect of lubricant oil properties on the performance of gasoline particulate filter
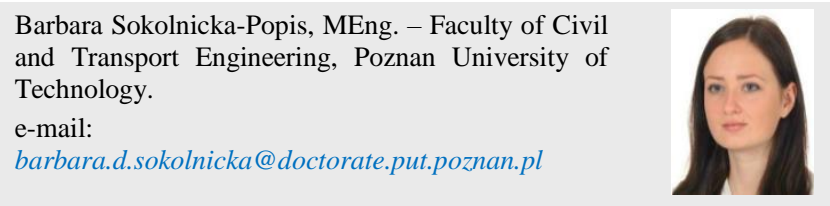

Maciej Siedlecki, MEng. - Faculty of Civil and Transport Engineering, Poznan University of Technology.

e-mail: maciej.siedlecki@put.poznan.pl
(GPF). SAE International Journal of Fuels and Lubricants 2016, 9(3), 650-658. https://doi.org/10.4271/2016-01-2287

[8] THAKRAL, N., PREMNATH, V., KHALEK, I. et al. Development of a burner-based test system to produce controllable particulate emissions for evaluation of gasoline particulate filters. SAE Technical Paper 2020-01-0389, 2020. https://doi.org/10.4271/2020-01-0389

[9] TSIAKMAKIS, S., CIUFFO, B., FONTARAS, J. et.al. Introducing a new emissions certification procedure for european light-duty vehicles: Monte Carlo simulation of the potential effect on fleet carbon dioxide emissions. Transportation Research Record. 2016, 2572(1), 66-77. https://doi.org/10.3141/2572-08

[10] YANG, J., ROTH, P., DURBIN, T. et.al. Gasoline particulate filters as an effective tool to reduce particulate and PAH emissions from GDI vehicles: A case study with two GDI vehicles. Environmental Science and Technology. 2018, 52(5), 32753284. https://doi.org/10.1021/acs.est.7b05641

Natalia Szymlet, MEng. - Faculty of Civil and Transport Engineering, Poznan University of Technology.

e-mail: natalia.r.szymlet@doctorate.put.poznan.pl

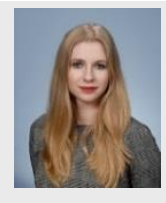

Dawid Gallas, MSc. - Faculty of Civil and Transport Engineering, Poznan University of Technology. e-mail: dawid.p.gallas@doctorate.put.poznan.pl

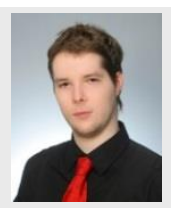

